\title{
EL SIN TÍTULO: UN RELATO ESTÉTICO DESDE LA PRÁCTICA ARTÍSTICA
}

\author{
Natividad Garbayo Alvero \\ Universidad del País Vasco / Euskal Herriko Unibertsitatea. Dpto. Arte y Tecnología
}

\section{Resumen}

El Sin Título es una obra audiovisual que da forma al fundamento empírico de la investigación sobre el comportamiento y desarrollo experimental del artista dentro y fuera del Laboratorio del Arte. La incertidumbre artística e intelectual nos planteó como artistas la importancia y la relación existente entre la práctica artística y la investigadora, generando una reflexión: ¿Qué investigan artistas que experimentan en y desde su práctica artística? Para poder abordar los fenómenos planteados por el sujeto creador, construimos un relato estético-visual con un enfoque metodológico experimental apoyado en la Ley de los Cambios del artista Jorge Oteiza. Nuestro interés por analizar y estructurar ese proceso de cambio fue conformando una estética de conocimiento que relacionaba lenguaje, escritura y pensamiento. Un discurso que en su creación audiovisual, combinó la lógica de los sentidos con el proceso de recuperación del yo, de lo sensorial y lo subjetivo con un marcado trasfondo poético.

Palabras clave: CONOCIMIENTO; ESTÉTICA; PRÁCTICA ARTÍSTICA

\section{THE UNTITLED: AN AESTHETIC STORY FROM ARTISTIC PRACTICE}

\section{Abstract}

The untitled is an audiovisual work that gives shape to empiric basis in investigation regarding the artist behaviour and experimental development inside and outside of the Art Lab. The artistic and intellectual uncertainty suggested as artists the importance and the relation existing between the artistic practice and the investigator, generating a reflection: What do artists that experiment in/from their artistic practice investigate? To tackle the phenomena set by the creator, we built an aesthetic-visual store with an experimental methodological focus based in the "Law of Changes" from the artist Jorge Oteiza. Our interest in analyzing and organizing this process of change brought up an aesthetic in knowledge that connected language, writing and thinking. A speech that in its audiovisual creation combined the senses' logic with the recovery of the self, the sensorial and the subjective with a well-marked poetic background

Keywords: KNOWLEDGE; AESTHETICS; ARTISTIC PRACTICE

Garbayo Alvero, Natividad. "El Sin Título: Un relato estético desde

la práctica artística". AusArt 6 (1): 183-194. D0I: 10.1387/

ausart.19473

\section{AUSART}




\section{PRESENTACIÓN: ¿QUÉ INVESTIGAN ARTISTAS QUE EXPERIMENTAN EN Y DESDE SU PRÁCTICA ARTÍSTICA?}

Jorge Oteiza elaboró un ensayo donde el ser humano como artista debía plantearse y resolver desde su perspectiva existencial, no limitándose a una visión periférica del arte como disciplina parcial. Fue la llamada Ley de Los Cambios lo que le permitió analizar tanto su comportamiento experimental como el del resto de artistas, atendiendo más a la imagen de un esquema que a una norma absoluta. Desde la condición vanguardista del arte para la vida, Oteiza encuentra que la evolución del proceso artístico responde a una especie de lógica, de buen sentido y de economía en el esfuerzo de la investigación.

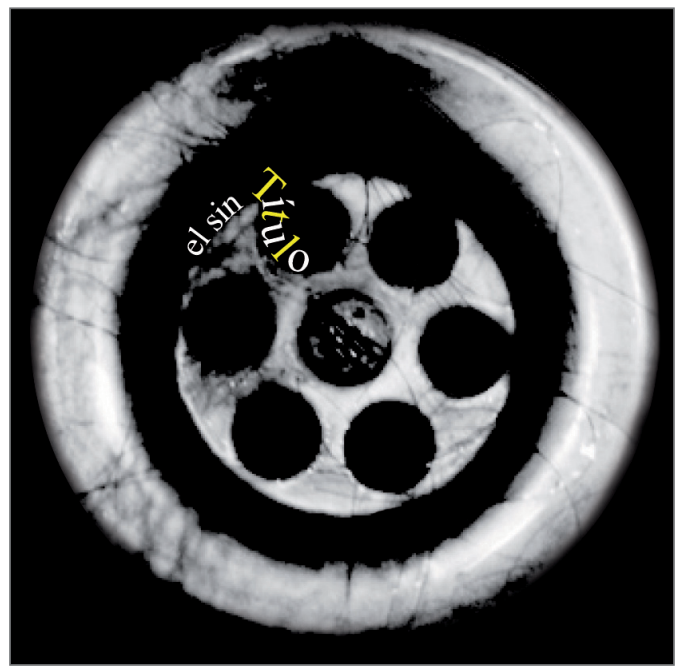

En opinión de Andrei Tarkovski (1996, $60)$, la función indiscutible del arte está enlazada con la idea del conocimiento, de aquella forma de efecto que se expresa como conmoción, como catarsis. Para Oteiza, las preguntas fundamentales que hacen del arte función ideológica, servicio espiritual de primera necesidad para la sociedad, para la vida, el artista las hace o las toma en la vida antes de entrar en el arte. Es en el arte donde tiene que contestarlas. Y cuando las ha contestado, el artista vuelve a la vida, graduado para la vida, con una nueva y entera libertad.

Una reflexión que dispone al artista en dos comportamientos revolucionarios distintos: antes, dentro del laboratorio del arte y luego en la vida (Oteiza 1990). Estos comportamientos conjugados con las teorías, falacias, ilusiones y perversiones de la intimidad profundizado por el filósofo José Luis Pardo en su teoría frutal de la intimidad, dan forma al valor plástico del relato audiovisual que lleva por nombre, el Sin Título. (Garbayo Alvero 2005) ${ }^{1}$

"Si el artista contemporáneo no concluye dentro del arte, el ser humano ${ }^{2}$ con una nueva sensibilidad existencial no nace, política- 
mente nuevo no empieza, perdido dentro de un largo y dramático aprendizaje que no sabe justificar ni concluir."

(Oteiza 1990, 11) $)^{3}$

\section{INTRODUCCIÓN: EL DESCUBRIMIENTO DE LA EXPRESIÓN}

La efusión por el aprendizaje de todo un sin fin de posibilidades y combinaciones de materia y forma.
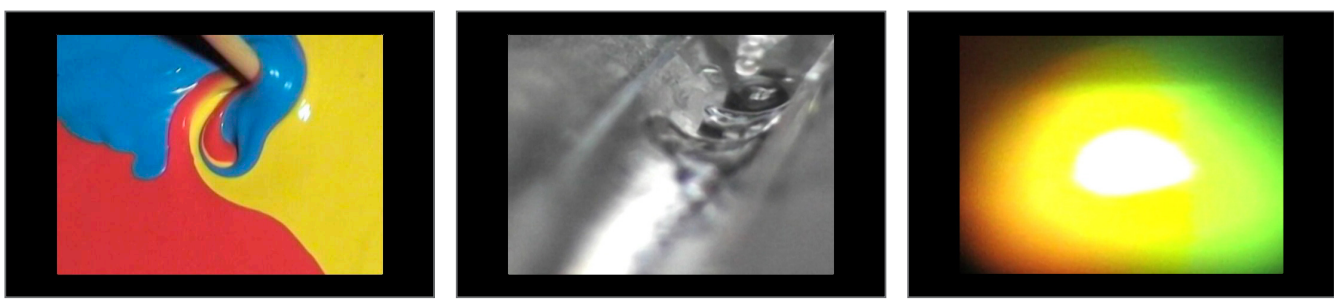

Fotogramas de la obra audiovisual El Sin título. Primera parte: del $00 \mathrm{~min} 26 \mathrm{~s}$ al $01 \mathrm{~min} 53 \mathrm{~s}$

\section{LAS CUALIDADES EXPRESIVAS DE LA ESTÉTICA}

Reaccionamos ante la Naturaleza con los sentimientos generales de lo bello o feo, agradable o desagradable. Los valores estéticos -bello, feo ${ }^{4}$, elegante, armonioso...- y los juicios de valor correspondientes están presentes prácticamente en la totalidad de la vida humana, no sólo con las obras de Arte, sino también con la prosa de la vida y con la Naturaleza.

Los sentimientos son una función de la propia representación que dan importancia a la expresividad y organizan nuestra respuesta en torno a ella. La expresividad reside en los sentimientos y emociones representados. Son anecdóticos e intentan complacer al receptor con una composición que de sentido al conjunto. Oteiza la define como ciencia particular operativa que trata los problemas fundamentales, internos, estructuras, clasificación y problemáticas a las que se enfrenta el artista dentro de su laboratorio experimental (Oteiza 1990, 24). 
La expresión se produce por acumulación formalista o informalista del espacio resultando una naturaleza expresionista, hablante, saliente, Ilena. La técnica acumulativa sirve para el desarrollo del proceso estético donde la libertad de comunicación está al servicio de la necesidad de expresión. La habilidad, la paciencia y el cuidado son cualidades admiradas en el dominio de la técnica, cuyo valor como base objetiva es la belleza, el realismo y la destreza en la respuesta estética.
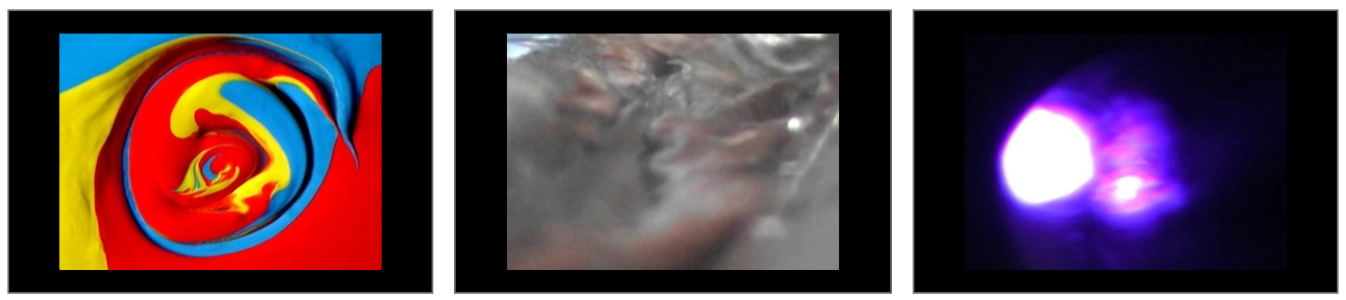

Fotogramas de la obra audiovisual El Sin título. Primera parte: del $02 \mathrm{~min} 16 \mathrm{~s}$ al $02 \mathrm{~min} 34 \mathrm{~s}$

\section{EL ARTISTA COMO EXPERIMENTADOR DE LENGUAJES COMPARADOS}

El artista graduándose en un lenguaje toma posesión automática de la realidad revelándola en el laboratorio del arte. Es el mundo de la tonalidad (Oteiza, 1990, 39): la estructura se llena y junto a la intensidad y el interés por la experiencia se garantiza autenticidad. El realismo y la destreza del estilo son un medio para expresar algo. Es más una cuestión de asociación que de representación, de invención que de descubrimiento. Parece como si la respuesta intuitiva fuera un juicio, siendo la única razón que podríamos dar de él: el hecho de que nos guste. Gustar y juzgar son ideas en este momento equivalentes.

La belleza de la expresión tiene que ver con la fuerza del sentimiento expresado. La representación como expresión, conjuga espacio y tiempo. En esa duración narrativa la belleza del medio surge del atractivo de las cualidades formales de la representación, donde se combinan y experimentan todas las materias naturales y lenguajes fabricados.

Oteiza expone al artista como un experimentador de lenguajes comparados (los fabricados y los naturales) que sociológicamente traspasa su modelo de experiencias, la praxis de su saber estético; diseñando en el laboratorio del arte un tipo operativo de sensibilidad que integra una libertad política de com- 
portamiento. Para Platón era evidente pensar en la belleza como una propiedad esencial de las personas: si lo hermoso es lo bueno de la especie, lo defectuoso, es lo feo de la especie. Si mantenemos esa evidencia, la idea de belleza permanecerá si en la representación mostramos y reflejamos su valor.
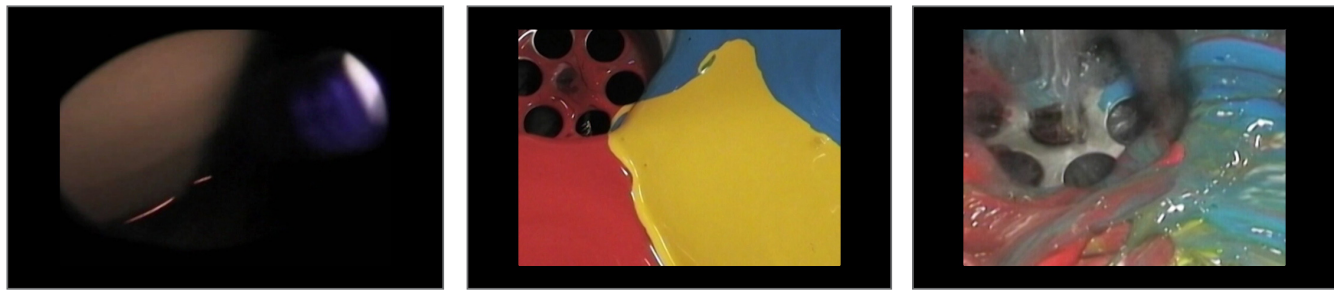

Fotogramas de la obra audiovisual El Sin título. Primera parte: del $02 \mathrm{~min} 16 \mathrm{~s}$ al $02 \mathrm{~min} 34 \mathrm{~s}$

\section{EL PRINCIPIO DE LA INTIMIDAD}

Los instrumentos técnicos nos ayudan a representarnos y a percibirnos tal y como nos escuchan, ven o leen los demás. Ese retraso del yo con respecto a su identificación, esa distancia que cada uno debe recorrer hasta llegar a sí mismo es el principio de la intimidad (Kristeva 2000, 72). Ser alguien consiste en que haya cosas que a uno mismo le importen más y menos, cosas que le gusten o le disgusten. La forma y el contenido de estas preferencias, los gustos y disgustos son evidentemente particulares, privados. La contradicción que se desgarra entre lo privado y lo público luchan a muerte en el interior de cada sujeto mostrando un sentimiento de la experiencia asumida como identidad. Ese realismo emocional de la expresión, su dinamismo dialogado y explorado por el medio hace confundir la intimidad con la privacidad del ser (Pardo 1996, 38).

La representación actúa en respuesta a la expresión, vaciando todo sentimiento. El préstamo del artista concluye desde que la obra vive su propia existencia. Su potencial energético, su sentimiento vital encuentra la forma expresiva y significante de la representación para no mostrar una simple reproducción. Lo estético es un fenómeno ligado casi de manera inevitable a lo creativo. Es una expresión artística que plasma la actividad mental donde la imaginación la organiza.

Como todo cuanto pertenece a la esfera de la cultura, la educación estética se completa con una educación paralela en la que las condiciones de vida, 
las experiencias individuales y los sistemas de valores del medio circundante ejercen una considerable influencia.

\section{DESARROLLO: EL VACÍO DE LA ATONALIDAD}

Se va perdiendo esa efusividad, la expresión se va anulando y entran a formar parte valores y planteamientos de contenido. Entramos en el sin sentido: se produce el vacío, la contención de la pulsión, el silencio, el grito. Es la prueba final de haber desmontado la expresión.
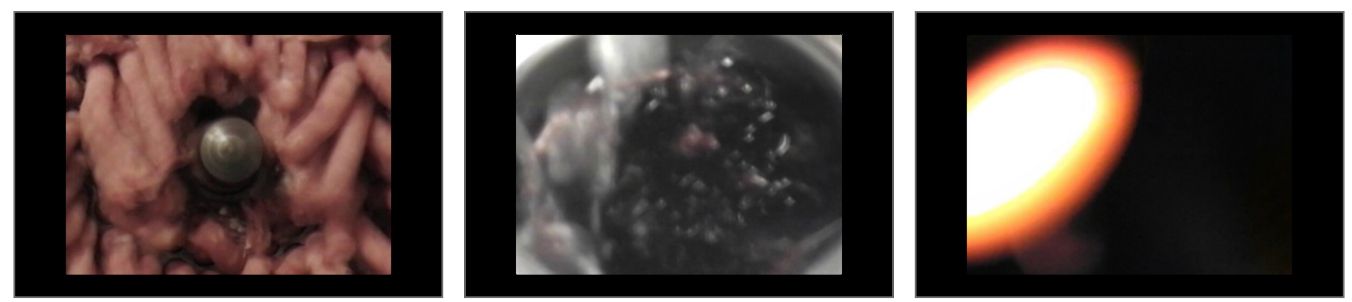

Fotogramas de la obra audiovisual El Sin título. Segunda parte: del $02 \min 35 \mathrm{~s}$ al $04 \mathrm{~min} 16 \mathrm{~s}$

\section{EL PUNTO DE FUGA Y SU ENCUENTRO EN LA REPRESENTACIÓN}

La física de la expresión desemboca en movimiento, confundiendo vida y naturaleza. Lo que en un principio era construcción de espacios exteriores de expresión, se sucede la creación de espacios interiores como soluciones puramente receptivas. La expresión se va desmontando, revelando el sentido y la significación del entorno. A su vez, la representación se apaga como expresión insistiendo en no hablar, no levantar la voz, necesitando un sentido curativo de sus limitaciones y sus miedos.

La ardua tarea de renovar preguntas y respuestas concluye la señal en la representación vacía: el mundo de la atonalidad (Oteiza 1990, 39). Esa nada elemental que nos figurábamos como punto de partida del saber es ahora punto de llegada, convirtiéndose en identificación espiritual con nuestra inti- 
midad personal. La falta de precisión para asumir un juicio y la capacidad de cuestionamiento convierte la intimidad del ser en un monstruo de encrucijada. Esa permanente tentación de abandono del camino hacia todas partes y ninguna abre al infinito el cuestionamiento de los sistemas de valores en una re-vuelta del sentido a la pulsión y viceversa (Kristeva 2000, 60), revelando la memoria y resurgiendo al sujeto con sus deseos y creatividad.

Es preciso sumergirse en las aguas turbias de la abyección, mancharse de su fango y heder por su porquería para poder extraer el tesoro de un concepto (Clément \& Kristeva 2000, 121).

La cultura sería un proceso particular sobre el que se desarrolla la humanidad puesto al servicio del Eros, condensando a los individuos aislados, a las familias, pueblos y naciones. La obligación moral tiene sus raíces en el deseo mismo, es la energía del deseo la que engendra su propia censura. No solamente el sujeto es libre a condición de "no ceder respecto a su deseo", sino que es "culpable de haber cedido a su deseo" (Kristeva 2000, 45). La conciencia transforma el deseo refrenado en remordimientos y en culpabilidad, pero también en autodestrucción, exigiendo una restricción de los deseos (y por tanto, de la libertad).
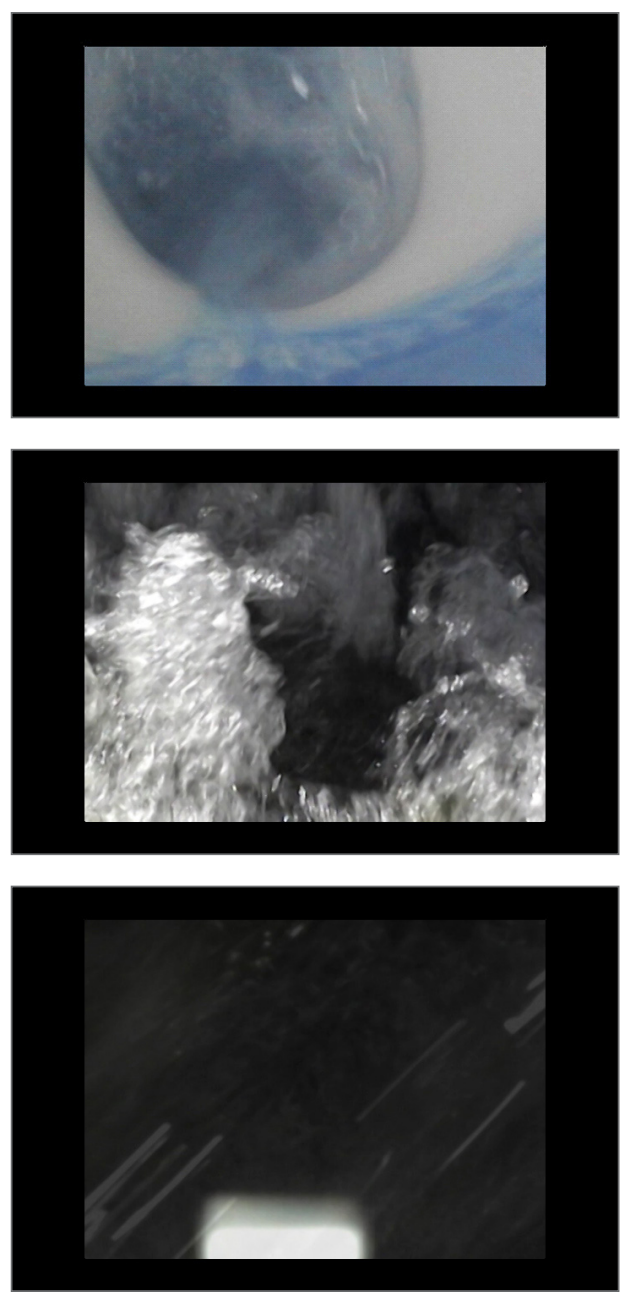

Fotogramas de la obra audiovisual El Sin título. Segunda parte: del $08 \mathrm{~min} 50 \mathrm{~s}$ al $10 \mathrm{~min} 42 \mathrm{~s}$ 


\section{EL ORDEN SIMBÓLICO COMO ESTRUCTURADOR DE LENGUAJE Y PENSAMIENTO}

La revelación se presenta como una caja negra, una habitación cerrada cuyo umbral sólo puede traspasarse en la intimidad precisando tiempo y espacios íntimos que sólo el arte puede construir. La misma señal vacía que marca la conclusión queda como una señal sagrada expresada desde lo estético. Esta cuestión de la génesis del vacío atiende a una intrincada red de pasiones, un encuentro que libera la representación de su materialidad entendiéndose enteramente espiritual. Por acercarse a esta vida (natural) muere siempre el arte, reapareciendo el sentimiento trágico (Oteiza 1990, 12).

Esta soledad es una consecuencia del pensar la vida a partir de la muerte, comunicando lo sagrado de ese instante (Clément \& Kristeva 2000) ${ }^{5}$. Es un espacio de precisión de sinceridad, una revuelta instantánea que atraviesa el cuerpo (abandonado) y que grita. Kant en la crítica del juicio entiende lo sagrado como lo sublime; un cortocircuito entre lo sensible y la razón que traza una moral.

El cuerpo bolsa de basura, es tanto masculino como femenino. Lo sagrado participa de todas las materias que Lacan clasificó con el nombre genérico de objeto de deseo: el detalle, lo parcial, el trozo de cuerpo que no es su totalidad e incluso sus desechos. Clasificando estos objetos de deseo, estarían los nobles (las lágrimas, el seno, la leche, el soplo, el cabello) y los innobles (los de debajo de la cintura, las secreciones sexuales, la orina y el excremento). En el judaísmo, la mancha y lo sagrado se tocan. En el monoteísmo, lo sagrado es simplemente... el amor. $Y$ en el psicoanálisis lo sagrado es siempre una purificación (Clément \& Kristeva 2000, 121).
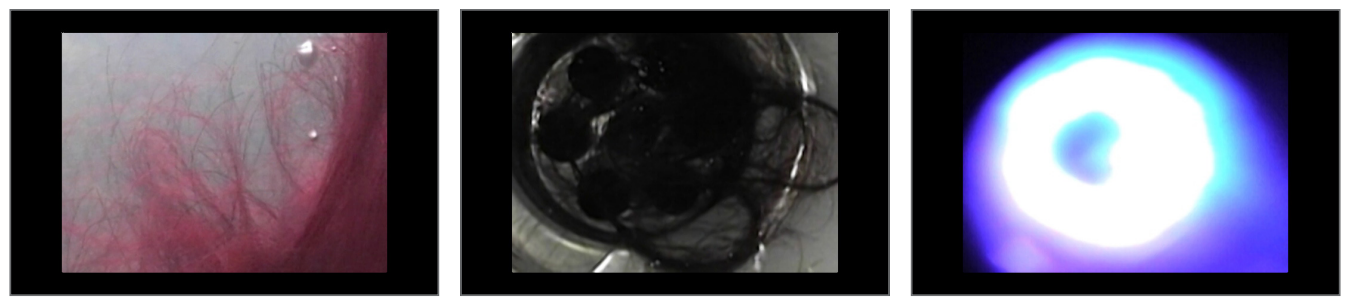

Fotogramas de la obra audiovisual El Sin título. Segunda parte: del $08 \mathrm{~min} 50 \mathrm{~s}$ al $10 \mathrm{~min} 42 \mathrm{~s}$ 


\section{EL OMBLIGO DE LOS SUEÑOS. LA MORADA DE LA INTIMIDAD}

Después de declarar que la soledad es la manifestación suprema de la intimidad, se describe como una confesión. El viaje posible traza una sutil conquista en el sentimiento y el entendimiento del límite que Freud llamó graciosamente el ombligo de los sueños. Se trata de atravesar la nada de uno mismo, vencer los pensamientos salvajes para alcanzar un conjunto de trazos y de sonidos que desafíen el entendimiento y eliminen toda esa porquería que ensucia el medio, ruina del concepto.

El presente sólo puede ser realmente efímero cuando hay un porvenir que pueda borrarlo o un pasado en el que pueda abismarse; de no ser así nada es pasajero sino que al contrario, todo se ralentiza, convirtiendo cada instante en un atolladero sin salida. Esa presencia en el tiempo y en el espacio que conjuga el encuentro con esos límites es lo que llamamos representación.

Solamente el ser humano logra expulsar a la realidad exterior unos seres - producto artístico- que sobrenadan en el río de recuerdos y permanecen latiendo, resistiendo a la descomposición. Toda esta clase de objetos tienen un mismo ser, el Ser estético, que constituye tanto su naturaleza como su principio superior.

Paradójicamente, el ángulo de decadencia es la ligazón a la vida. Esas inclinaciones son los poros por los que la nada penetra en el ser y la muerte en la vida, siendo los poros por los que uno respira. Se siente vivir porque mueres por aquello a lo que te inclinas, porque a ello entregas la vida, habiendo algo por lo que dar la vida, algo que hace gritar de placer o de dolor, algo que, si no hace vivir, hace que vivir merezca la pena (Pardo 1996, 45).

\section{CONCLUSIÓN: EL ARTE COMO CURA DEL SENTIMIENTO CRÍTICO}

Planificar la búsqueda de una recuperación del equilibrio del ser humano con su nueva realidad. El encontrar e inventar un orden es el máximo exponente del aprendizaje, proponiendo para su seguimiento, un punto de partida: del espíritu al medio. 

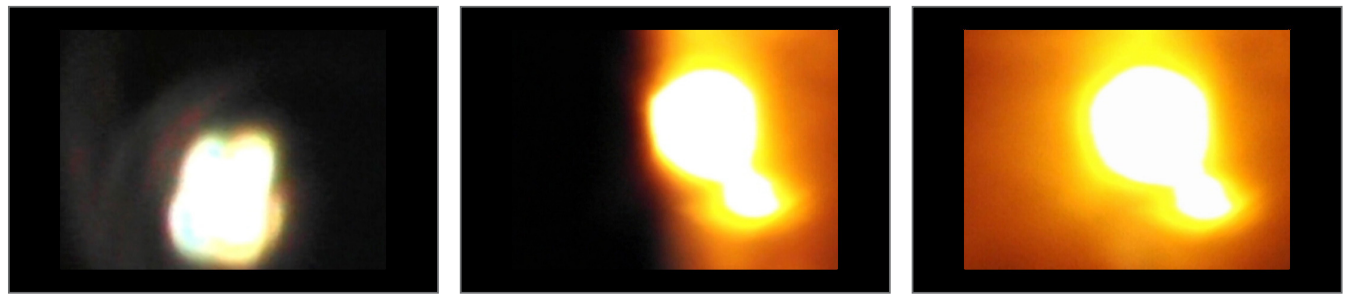

Fotogramas de la obra audiovisual El Sin título. Tercera parte: del $10 \mathrm{~min} 43 \mathrm{~s}$ al $11 \mathrm{~min} 10 \mathrm{~s}$

\section{LA ESTÉTICA COMO ACCESO ESPIRITUAL DEL SUJETO AL ARTE}

El Arte (lo artístico) es el mundo que debe abrirse tras el fin del proceso experimental. El vacío y el silencio se inauguran en el instante en el que el arte termina, otorgando la plenitud de su naturaleza. Es preciso conquistar aquel instante original del ser. La autenticidad del artista se caracteriza por trascender de lo funcional, encontrando su implicación en el sentido latente de la vida. En su visión profunda de lo real, el artista conecta con contenidos que subyacen en el inconsciente colectivo.

Diremos estética para entender el acceso espiritual del sujeto al arte. Para alcanzar la representación libre del artista hay que ir más allá de la oscuridad inmediata (que sin duda simboliza la materia) para que el pensamiento se calme.

\section{LOS TRES MOMENTOS DE LA INTIMIDAD}

Los tres momentos de la intimidad corresponden a tres fenómenos que nos sostienen en la existencia: el espacio (íntimo), el tiempo (íntimo) y el arte (de sí mismo). La intimidad no hace posible el lenguaje pero lo hace real, le confiere ser. El lugar íntimo no tiene señales de orientación ni marcas direccionales. Sólo puede ser contemplado, reconocido, habitado y sentido a medida que nos adentramos en la intimidad. Este espacio crea proximidad entre quienes conforman el círculo celeste que pone en comunicación directa la oscuridad con la luz, lo más profundo con lo más elevado, remitiéndonos a la concepción 
de un espacio trascendental en el que el cielo y la tierra se encuentran. Este espacio visto desde la profundidad es donde permanecemos ocultos.

Todo artista, como creador de lenguaje, escritura y pensamiento constituye una operación en la que estéticamente supera la contradicción entre verdad e incertidumbre. La verdadera lógica de la operación creadora es que por ella emerge de sentido el ser humano, naciendo al borde de la nada, caminando a ambos lados, de la nada al ser y vuelta. El sentido sigue aflorando y el inconsciente sigue sorprendiendo. El estar en estado de escritura, en una especie de fuera-del-tiempo, nos hace permanecer en un pasaje de la experiencia, en lo esencial del borrador.

\section{LA INTEMPORALIDAD DEL INCONSCIENTE: EL INAUDITO FUERA DE TIEMPO}

AI Yo que habla simple y solitario, inextenso y sin profundidad, se añade entonces el Yo que (se) escucha a Sí Mismo hablar, que recibe la voz que emite. No se puede hablar y escuchar al mismo tiempo. Entre el Yo y el Sí Mismo transcurre el tiempo, abriendo un lugar en donde el Yo se descubre a Sí Mismo, haciéndose ser alguien. Toda experiencia entra en un razonamiento con la geometría del tiempo: o se carga la intención experimental en el espacio, o se carga la intención experimental en el tiempo (Oteiza 2007, 14). Llegar a una conclusión después de desmontar la expresión, pone en conocimiento un nuevo sentimiento de liberación espiritual. Ese intento de poner un orden al pensamiento estético tras las mutaciones de la expresión, hace surgir una nueva sensibilidad del ser humano para la vida, elaborando una realidad libre, capaz de protegerle (Oteiza 1990, 36-7).

Hace falta arreglar el fuera de tiempo y el cuestionamiento permanente de todo. Son en esas épocas de suspenso donde el cuestionamiento permanece como el único pensamiento posible. El inaudito "fuera del tiempo" caracteriza la intemporalidad del inconsciente. Mientras la existencia humana está intrínsecamente ligada al tiempo, la experiencia analítica nos reconcilia con ese "fuera del tiempo" que es el de la pulsión, y particularmente de la pulsión de muerte. Hacer un sujeto de revuelta perpetua, de cuestionamiento incesante le hace estar en estado de perpetuo renacimiento. 


\section{Referencias}

Aguilera Cerni, Vicente, dir. 1979. Diccionario del arte moderno: Conceptos-ideas-tendencias. Valencia: Fernando Torres

Clément, Catherine \& Julia Kristeva. 2000. Lo femenino y lo sagrado. Traducción de Maribel García Sánchez. Madrid: Cátedra

Descartes, René. (1637) 1970. Discurso del método; Meditaciones metafísicas. Traducción, prólogo y notas de Manuel García Morente. Madrid: Espasa-Calpe

Eco, Umberto. (1963)1978. La definición del arte. Traducción de Ramón de la Iglesia. BarceIona: Martínez Roca

Ferrater Mora, José. 1972. Diccionario de filosofía abreviado. Texto preparado por Eduardo García Belsunce y Ezequiel de Olaso. Buenos Aires: Edhasa

Gadamer, Hans-Georg. (1977) 2009. La actualidad de lo bello: El arte como juego, símbolo y fiesta. Traducción de Antonio Gómez Ramos; introducción de Rafael Argullol. Barcelona: Paidós

Irigaray, Luce. 1992. Yo, tú, nosotras. Traducción, Pepa Linares. Madrid: Cátedra

Kristeva, Julia. 2000. El porvenir de una revuelta. Traducción del francés por Lluís Miralles. Barcelona: Seix Barral

Oteiza, Jorge. 1990. Ley de los cambios. Donostia-San Sebastián: Tristan-Deché

Pardo Torío, José Luis. 1996. La intimidad. Valencia: Pre-Textos

Rosales Barrios, Alberto, ed. 1999. Jorge Oteiza: Creador integral. Jaione Apalategi et al. Pamplona: Universidad Pública de Navarra.

Tarkovski, Andrei. (1986) 1996. Esculpir en el tiempo: Reflexiones sobre el arte, la estética y la poética del cine. Traducida por Enrique Banús Irusta. Madrid: Rialp

\section{Notas}

${ }^{1}$ Relato audiovisual que aúna sonido e imagen en movimiento. Imagen y contenido audiovisual realizado por Natividad Garbayo Alvero. Música compuesta por Jon Ulecia Leoz. Duración: $11 \min 10 \mathrm{~s}$.

${ }^{2}$ Proponemos ser humano en vez del hombre (utilizado por Oteiza) como sustantivo que designa indiferentemente a individuos de uno y otro sexo.

${ }^{3}$ Jorge Oteiza: Conclusiones de urgencia estética y política para el artista de hoy, ponencia de 1964.

${ }^{4}$ Karl Rosenkranz publicó en 1853 una Estética de lo feo.

${ }^{5}$ Punto de encuentro de la sexualidad y el pensamiento, del cuerpo y del sentido, esencial para una mujer.

\footnotetext{
(Artículo recibido 19-03-18; aceptado 02-05-18)
} 